\title{
Enzyme-modified carbon-felt based flow-type amperometric glucose biosensor using oxidase/peroxidase-bienzyme system
}

\author{
Yasushi Hasebe $^{1}$, Takashi Watanabe ${ }^{1}$ \\ ${ }^{1}$ Department of Life Science and Green Chemistry, Saitama Institute of Technology, \\ Fukaya, Saitama 369-0293, Japan \\ hasebe@sit.ac.jp
}

\begin{abstract}
:
Amperometric flow-injection analysis (FIA)-type glucose biosensor was fabricated using porous carbonfelt modified with glucose oxidase (GOx) and horseradish peroxidase (HRP). Enzyme-immobilization (adsorption) protocol and operational parameters were optimized. The obtained GOx/HRP-CF-based FIA-type glucose biosensor showed the sensitivity $(2.07 \mu \mathrm{A} / \mathrm{mM})$, the limit of detection $(0.014 \mathrm{mM})$, and linear range (0.03 to $3 \mathrm{mM})$. Interference by ascorbic acid $(0.5 \mathrm{mM})$ could be cancelled by the control of applied potential. The RSD for 63 consecutive injection of $10 \mathrm{mM}$ glucose was $3.71 \%$. The biosensor was applied for the determination of glucose in various beverages, and the analytical results obtained by the sensor were in fairly good agreement with those by conventional enzyme-based spectrophotometry.
\end{abstract}

Key words: Carbon-felt, amperometric FIA-type glucose sensor, bienzyme system.

\section{Introduction}

Carbon-felt (CF) is a microelectrode ensemble of micro carbon fibers (ca. 7 um in diameter) and possesses a random three dimensional structure. CF has high surface area and shows high conductivity and high electric efficiency. In addition, the high porosity (> 90\%) of CF permits a very low diffusion barrier of solution flow. Therefore, if enzymes can be successfully immobilized onto the CF, it would be useful as a working electrode unit of the electrochemical flow-type biosensor. From this view points, we have been studying simple, convenient and effective protocols for enzyme immobilization onto the CF surface to develop CF-based flow-type biosensors [1-4]. Among various enzyme immobilization methods, physical adsorption is the simplest and the most convenient. In previous study, we have reported that co-adsorption of horseradish peroxidase (HRP) with some organic dyes (such as thionine, Th) onto CF is effective for highly sensitive amperometric determination of $\mathrm{H}_{2} \mathrm{O}_{2}$ based on the direct electron transfer (DET) between HRPactive heme-center and the CF electrode $[3,4]$. This HRP/Th-adsorbed CF showed an excellent operational stability (repetitive 100 sample injection of $0.1 \mathrm{mM} \mathrm{H} \mathrm{H}_{2}$ induced no serious current decrease). Therefore, the combination of
$\mathrm{H}_{2} \mathrm{O}_{2}$-generating oxidase with this HRP/Th-CFbased flow detector enables sensing of various oxidase-substrates. In this study, we selected glucose oxidase (GOx) as a model enzyme, and prepared GOx-HRP co-adsorbed CF for glucose sensing. Enzyme-immobilization protocol and operational parameters were optimized, and the sensor performances were evaluated for practical use.

\section{Experimental}

Glucose oxidase (GOx; EC 1.1.3.4 from Aspergillus niger) and horseradish peroxidase (HRP; EC 1.11.1.7) were purchased from Wako Pure Chemicals and used as received. Thionine chloride (Th) was purchased from Tokyo Kasei Kogyo Co. All of the other chemicals were of the heist grade available, and were used without further purification. A CF sheet was obtained from Nippon Carbon Ltd. 0.1 M Britton-Robinson buffer was used throughout the experiment. A glucose stock solution (2 $\mathrm{M}, 10 \mathrm{~mL})$ was prepared with $0.1 \mathrm{M}$ Britton-Robinson buffer.

GOx and HRP-coadsorbed CF was prepared by immersing the CF into enzyme solution. To evaluate the interfacial properties of enzymeadsorbed CF, electrochemical impedance spectroscopy (EIS) was done in a conventional one-compartment three-electrode system consisting of enzyme-adsorbed CF with platinum 
lead wire as working electrode, a platinum wire auxiliary electrode, and $\mathrm{Ag} / \mathrm{AgCl}$ reference electrode. A deoxygenated $0.1 \mathrm{M}$ BrittonRobinson buffer containing $0.25 \mathrm{mM}$ hydroquinone was used as a supporting electrolyte solution. The flow-injection analysis (FIA) system are shown in Fig. 1. The system is composed of a double-plunger pump with six way injection valve and the GOx/HRP-CF-based electrochemical flow-through detector connected to electrochemical analyzer.

A

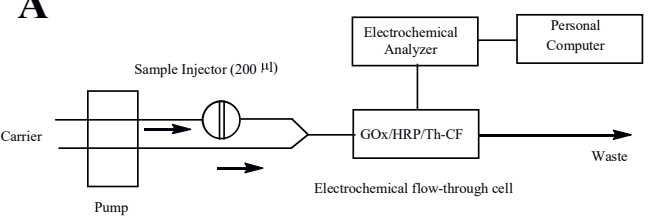

B

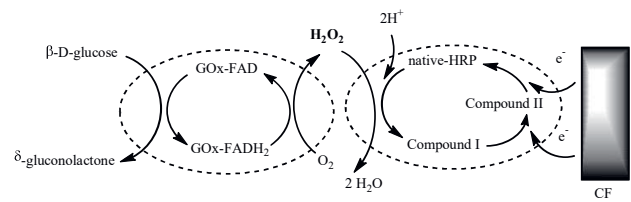

Fig. 1 (A) Schematic diagram of the GOX/HRP/Thadsorbed CF-based FIA biosensor. (B) Detection scheme for glucose by the FIA biosensor

\section{Results and Discussion}

First, we compared two-kinds of enzyme adsorption methods, 1) one-step simultaneous adsorption of GOx and HRP, and 2) step-wised separate adsorption (first HRP was adsorbed and then GOx was adsorbed). To obtain larger response, the step-wised adsorption was effective (5 to 8 time larger response) as compared to one-step simultaneous adsorption, probably because 2 layered structure (HRP at the vicinity of the $\mathrm{CF}, \mathrm{GOx}$ facing to solution) formed would be effective for efficient cascade reaction as shown in Fig. 1 (B). After optimization of adsorption conditions (GOx conc., $\mathrm{pH}$, adsorption time), and operational parameters (carrier flow rate and $\mathrm{pH}$ ), we studied interference by ascorbic acid. When applied potential was set at $-0.05 \mathrm{~V}$ (vs. $\mathrm{Ag} / \mathrm{AgCl}$ ), interference by $0.5 \mathrm{mM}$ ascorbic acid toward 10 $\mathrm{mM}$ glucose response was completely cancelled. Fig. 2 shows calibration curve of glucose. Linear range was 0.03 to $3 \mathrm{mM}$, sensitivity was $2.07 \mu \mathrm{A} / \mathrm{mM}$, and the limit of detection was found to be $0.014 \mathrm{mM}(\mathrm{S} / \mathrm{N}=3)$. Operational stability was checked by repetitive 63 injection of $10 \mathrm{mM}$ glucose (see Fig. 3). RSD was $3.71 \%(n=63)$. The determination of glucose in beverages was performed by using the present flow-biosensor utilizing calibration method. All samples were diluted by 200-900 times by using an airsaturated $0.1 \mathrm{M}$ Britton-Robinson buffer using as carrier. The analytical results obtained by the sensor were almost agree with those obtained by the spectrophotometry kit method. Finally, longterm stability of the GOx/HRP-CF was examined. When not in used, the GOx/HRP-CF was stored in the buffer at $4{ }^{\circ} \mathrm{C}$ in refrigerator. The GOx/HRP-CF retained its original activity ca. $77 \%$ during 7 days storage, ca. $50 \%$ after 14 days, and ca.32 \% after 50 days. Desorption and conformational change of the adsorbed enzymes would be possible reasons.

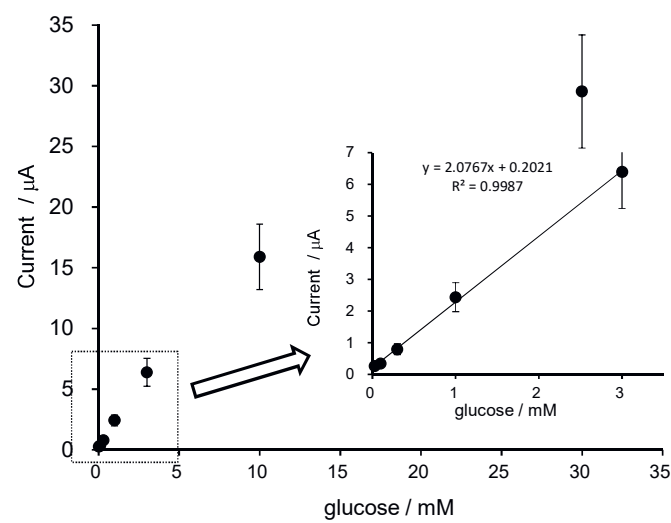

Fig. 2 Calibration curve of glucose obtained by the present GOX/HRP-CF-based FIA biosensor.

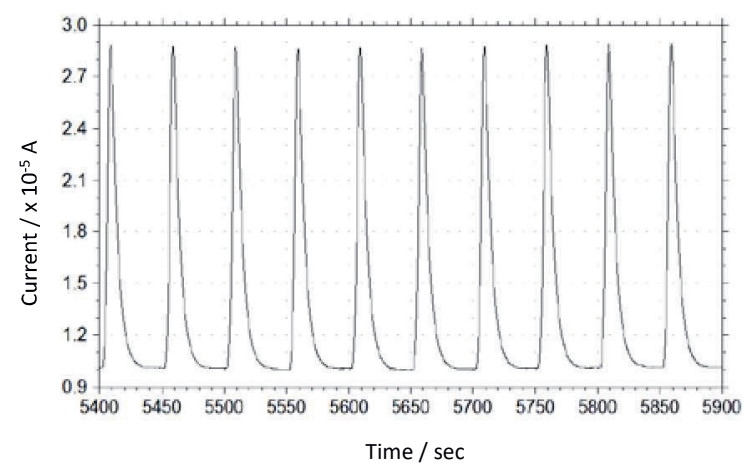

Fig. 3 Typical peak current responses to repetitive injections of glucose $(10 \mathrm{mM})$ obtained by the FIA biosensor.

\section{References}

[1] Yue Wang, Yasushi Hasebe, J. Pharm. Biomed. Anal., 57, 125-132 (2012): doi.org/10.1016/j.jpba.2011.08.021

[2] Yue Wang, Yasushi Hasebe, Electroanalysis, 23, 1631-1637 (2011); doi: 10.1002/elan.201100005

[3] Yue Wang, Yasushi Hasebe, Anal. Sci., 27, 401 (2011): doi.org/10.2116/analsci.27.401

[4] Yue Wang, Yasushi Hasebe, Materials, 7, 1142 (2014); doi:10.3390/ma7021142. 